\title{
Research on Measures to Develop Information Technology Education
}

\author{
Zhiqiang $\mathrm{Xu}$ \\ Department of Physics and Technology \\ Kunming University \\ Kunming 650214, China
}

\begin{abstract}
How to properly apply information technology in classroom teaching to improve the quality of teaching, and to promote the deepening of teaching reform is a question which is worth considering. This paper focuses on the application of computer information technology in teaching management, learning management and school management. The role of computer and mobile information technology education management is studied. From the view of theoretical research, it is not only about the expansion and extension of the existing computer information technology and mobile information technology applied to school education, but also a new research direction of computer information technology as well as related mobile information technology applied to education. The main purpose is to study the application status of modern mobile information technology. It has been found that the development of mobile information technology in modern education is not rapid and a lot of research is needed. So corresponding improvement me asures are proposed for its development.
\end{abstract}

Keywords-quality of education; information technology; improvement measures

\section{INTRODUCTION}

Information technology includes collection, processing and transmitting of data and information. It applies information technology to education and teaching activities, which utilizes its powerful acquisition, transmitting and processing technologies to improve the quality of education and promote the development of students. Under the influence of modern information technology, there is an unprecedented development trend in all fields, while there is no exception in the field of education. Information technology, represented by computers and networks, not only changes people's work and lifestyle, but also changes education and learning. Information technology has greatly expanded the space and time constraints in for different forms of education. Advanced information technology makes it easier to share educational resources and greatly enhances the freedom of learners' choices. A major breakthrough is being made for the traditional teaching model. Therefore, education is facing the most profound changes. It is not the major changes in the form of education and the way of learning but the far-reaching influence of educational ideas, concepts, methods, content and methods. Thus, many countries are working hard to implement information technology education. Information technology has been using in education and teaching. It has also become a useful tool for assisting schools in a range of management. Computing information technology is utilized to promote students to take the initiative in learning efficiently.

Information technology is both an independent branch of disciplines and the foundation of all disciplines, which is a major skill branch. It has been deepened into a fundamental approach to transforming human production and lifestyle. Information technology occurs and develops due to the need of information communication. The advancement of information technology has expanded the time and space for information communication. The most essential requirement for the formation and development of civilization is communication. As information technology becomes more and more widely infiltrated into the fields of teaching, economics and politics, the information civilization that has swept the world has constituted and promoted the civilization development of the whole society. From the actual development of society, the foundation has been laid for cultivating the future citizens of the information society. It is necessary to seize the opportunity, catch up with the international level in the process of global information construction competition.

\section{FOCUS ON EFFECTIVE ABILITy DEVELOPMENT}

Information technology is the basic characteristics of the information society and education. It is also an important criterion for measuring the world's development towards modernization. Thus it makes the cultivation of computer literacy particularly important, which is necessary to rationally and practically formulate many learning plans and goals in cultivating information literacy, linking global information technology through the network. Information technology whose core is the computer, is constantly and profoundly affecting people's life and production methods, imperceptibly affecting all areas of society. So there is no exception in the field of education. Information technology has become one of the most rapid and far-reaching important sciences and technologies in modern society, which makes information literacy an important foundation of the information society. It is necessary to cultivate a series of new abilities, such as how to filter and acquire information quickly and accurately from a large amount of information, how to cultivate the ability in order to identify information accurately, and how to cultivate the ability of one's creativity to process information. A basic ability to use and analyze information should be required. In 
the process of the changing environment for information technology education in the world, if people want to adapt to the trend of world development and occupy a place in the world trend, the information technology education must be first popularized. Through the information technology curriculum, the learners' abilities to acquire, transmit, process and apply information can be cultivated, which will lay a solid foundation for their future adaptation to the information society. "Tools can only be fully understood through application. People are always actively using tools, not acquiring them. The richness of the tools can be constantly understood while they are used.” Therefore, when information technology is taught, teaching should be focused on providing an environment in which information technology is used to solve problems. According to Dewey's “Learn by doing” concept, a real learning activity situation should be created in the task-driven and contextual way. Information technology can be learned in the process of solving problems in real life [1].

\section{INTEGRATE EDUCATIONAL TECHNOLOGY INTO ADVANCED INFORMATION SYSTEMS}

Education modernization is indispensable for modern information technology. Modern education technology is a new field of education reform. The application of modern information technology in education is a decisive factor. The current curriculum reform is mainly to strengthen the process of modern consciousness. It is necessary to vigorously promote the integration of modern information technology and curriculum [2]. "Strive to promote the combination of information technology disciplines and subject teaching, and to encourage the extensive application of information technology in the teaching of other disciplines. Exploring the integration of information technology and other topics is a special issue that should be paid special attention to in the development of information technology education." Integration has made great changes to the traditional teaching model [3]. The emerging technologies such as the Internet of Things and Cloud Computing have provided new directions for research on mobile information technology. The combination of the emergence of the Internet of Things and Cloud Computing will bring greater development to education information, bringing more and richer innovative applications and services. It will also cause great changes in both teaching and management, and eventually in the level of educational information[4]. Mobile learning is an inevitable trend for modern education and teaching. Various mobile platforms which provide corresponding infrastructure for mobile learning should be developed by applying to advanced mobile information technology,

It was thought that mobile education had no limit of time, address, and personalized service. But in fact, it has its own disadvantages. Because the hardware conditions of hand-held mobile devices are limited, multimedia information such as pictures cannot be displayed on them, and such information is often essential for learning common sense. However, with the massive spread of the Internet and the cross-domain advancement of multimedia devices, many mobile devices are able to meet the needs of daily life and work. To some extent, the power of hand-held mobile devices is now more suitable for certain specific traditional educational equipment. Data analysis shows that the most contents of information technology and curriculum research are the most abundant, which reflects the trend of curriculum reform. At present, the development of information technology application is the integrating of information technology into other courses. It is affecting all aspects of teaching. At the same time, it brought some problems. This has led to a reduction in the use of information technology in other aspects of education, especially in the setting of information technology courses. It also shows that most of the education platforms are related to the combination of distance education and information technology, the development of new education platforms and the integration of information technology. Although there are few studies on mobile information technology at this stage, the research on education platform provides a lot of references for the subsequent research on information technology such as mobile learning.

\section{STRENGTHEN THE INTERACTION WITH LEARNERS}

Interaction is the soul of teaching. No matter how good a teaching content is, it is not effective if there is a lack of interaction with the learners. Interactive sessions should be set up as much as possible so that learners can learn actively. Appropriate interaction can not only improve the learner's interest, but also optimize the teaching effect. In addition, teachers can get feedback from the learners' learning effect in the interaction process. For example, some questions about the knowledge points mentioned in the first half of the video can be set in the middle of the time progress bar of the recorded video when asking learners to watch the video on the online education platform. If the learners answer the questions correctly, the next half of the video will continue to be played. If the learners' answers are wrong, a prompt box will jump out to explain the correct option and remind him to look back the video. If such a link can be added to an ordinary teaching video, the learners' attention will be improved greatly. The lack of interaction is the most obvious deficiency in the current online and the traditional education models, which deserves attention. The deeper the interaction is, the more feedback will be got. Online education judges learners' learning mastery through continuous feedback, which can scientifically plan learners' learning contents. It is the premise of intelligent humanized teaching. Teachers should use rich modern mobile information resources to complete teaching objectives, enrich teaching tools, and improve teaching efficiency [5].

The result of Internet and Education must be a fundamental change in the way of teaching and learning for traditional teaching. In the era of Internet, information technology education is gradually integrated into the information, and has achieved some achievements. On the one hand, in the curriculum resources, the construction of quality courses for information technology education, the construction of sharing courses, the network teaching platform, and the micro-classes are constantly improving. On the other hand, there are many discussions in the domestic academic circles on the information technology education. Many teachers who are in the practice of teaching are trying to use the information communication media such as Weibo, WeChat and QQ to open up new 
channels for teachers and students to use information technology to assist classroom teaching. The current research lacks the theoretical discussion and practical exploration of the real information classroom construction. The construction of information-based curriculum resources must come from the real needs of front-line teaching.

\section{CONCLUSION}

Information technology is only a means to assist students in learning to achieve the expected teaching goals. Teachers need to use the teaching objectives, teaching contents and students' actuality in a timely and appropriate manner in classroom teaching. They should not neglect local conditions. Teachers should not make multimedia the "independent media" in the classroom. Mobile learning can not replace classroom learning. [6] The competent education department should increase the training of teachers' use of information technology, adopting the combination of "training and self-study" to increase training from the production of courseware and the use of courseware; some teachers should be trained first and then they can train the other teachers in the school. Experts and technicians can also be invited to schools for training. Besides, the application of information technology should be incorporated into the teacher's promotion training curriculum system to supervise the teachers' learning. After all, Classroom teaching is an interactive process. The application of information technology should become a booster for cooperative learning. Having man-machine dialogues and using PowerPoint, Flash and Authorware can stimulate learners' interests in learning, which in return improves teaching efficiency. Information technology teachers should combine the contents of information technology with the actual learning tasks according to the concept of curriculum integration. They should use these practical background questions to arouse the interest in learning information technology from other disciplines or problems in real life.

\section{REFERENCES}

[1] Jianping Wang. The Transformation of Digital Campus and Teaching Model [J]. Teaching and Education. 2003(16)

[2] Hao Song , Xinsheng Hu, Zhongpei Zeng. Design and Implementation of Universal Paperless Operation System Based on Network[J]. China Distance Education. 2003(09)

[3] Li Lin. A preliminary study on the construction of "digital campus" in primary and middle schools [J]. Electro-educational Research. 2003(04)

[4] Lihua Song, Guifang Wang. On Information Technology and Disciplinary Integration [J].Sci-Tech Information Development \& Economy. 2003(12)

[5] S.L. Wurster. Internet in the schools, Tech Tren\}ls, March 1997,Vo1.42 No. 2

[6] J.E. Kemp. The Instructional Design Process, R.R. Donnelley \& Sons Company,1985 